\title{
Interleukin-1 $\beta$ enhances non-rapid eye movement sleep when microinjected into the dorsal raphe nucleus and inhibits serotonergic neurons in vitro
}

\author{
Alfredo Manfridi, ${ }^{1,2}$ Dario Brambilla, ${ }^{1,2}$ Susanna Bianchi, ${ }^{1,2}$ Maurizio Mariotti, ${ }^{2,3}$ Mark R. Opp ${ }^{4}$ and Luca Imeri ${ }^{1,2,4}$ \\ ${ }^{1}$ Institute of Human Physiology II, \\ 2'Giuseppe Moruzzi' Centre for Experimental Sleep Research, and \\ 3'Luigi Sacco' Department of Clinical Sciences, University of Milan Medical School, Via Mangiagalli 32, I-20133 Milano, Italy \\ ${ }^{4}$ Department of Anaesthesiology, University of Michigan Medical School, Ann Arbor, Michigan, USA
}

Keywords: cytokines, guinea-pig, neuroimmunology, rat, serotonin

\begin{abstract}
Interleukin-1 (IL-1) and IL-1 receptors are constitutively expressed in normal brain. IL-1 increases non-rapid eye movements (NREM) sleep in several animal species, an effect mediated in part by interactions with the serotonergic system. The site(s) in brain at which interactions between IL-1 and the serotonergic system increase NREM sleep remain to be identified. The dorsal raphe (DRN) is the origin of the major ascending serotonergic pathways to the forebrain, and it contains IL-1 receptors. This study examined the hypothesis that IL-1 increases NREM sleep by acting at the level of the DRN. IL-1 $\beta(0.25$ and $0.5 \mathrm{ng})$ was microinjected into the DRN of freely behaving rats and subsequent effects on sleep-wake activity were determined. IL-1 $\beta 0.5 \mathrm{ng}$ increased NREM sleep during the first $2 \mathrm{~h}$ post-injection from $33.5 \pm 3.7 \%$ after vehicle microinjection to $42.9 \pm 3.0 \%$ of recording time. To determine the effects of IL- $1 \beta$ on electrophysiological properties of DRN serotonergic neurons, intracellular recordings were performed in a guinea-pig brain stem slice preparation. In 26 of 32 physiologically and pharmacologically identified serotonergic neurons, IL-1 $\beta$ superfusion $(25 \mathrm{ng} / \mathrm{mL})$ decreased spontaneous firing rates by $50 \%$, from $1.6 \pm 0.2 \mathrm{~Hz}$ (before IL-1 $\beta$ superfusion) to $0.8 \pm 0.2 \mathrm{~Hz}$. This effect was reversible upon washout. These results show that IL-1 $\beta$ increases NREM sleep when administered directly into the DRN. Serotonin enhances wakefulness and these novel data also suggest that IL-1 $\beta$-induced enhancement of NREM sleep could be due in part to the inhibition of DRN serotonergic neurons.
\end{abstract}

\section{Introduction}

Although interleukin-1 (IL-1) was originally described as a product of the peripheral immune system, there is now ample evidence that IL-1, IL-1 receptors and the IL-1 receptor antagonist are constitutively expressed in normal brain (Vitkovic et al., 2000). IL-1 modulates behaviours such as feeding, sexual behaviour, social exploration, locomotor activity and sleep (Opp \& Imeri, 1999). IL-1 consistently has been shown to enhance non-rapid eye movement (NREM) sleep and inhibit rapid eye movement (REM) sleep in several animal species (Terao et al., 1998; Opp \& Imeri, 1999; Krueger \& Fang, 2000). Moreover, central administration of the IL-1 receptor antagonist (Opp \& Krueger, 1991) or of antibodies directed against IL-1 reduces spontaneous NREM sleep in normal animals and inhibits the physiological NREM sleep rebound that follows sleep deprivation (Opp \& Krueger, 1994a, b). IL-1 mRNA expression in rat brain exhibits diurnal variation with greater levels during the light (rest/sleep) period than during the dark (active) period (Taishi et al., 1997) and increases during sleep deprivation (Mackiewicz et al., 1996). IL-1 is detected more frequently in plasma samples taken from humans during sleep than during waking (Gudewill et al., 1992). IL-1-like activity in cerebrospinal fluid of cats varies in phase with the sleep-wake cycle

Correspondence: Dr Luca Imeri, as above.

E-mail: luca.imeri@unimi.it

Received 12 February 2003, revised 13 June 2003, accepted 17 June 2003
(Lue et al., 1988) and IL-1 plasma levels in humans peak at sleep onset (Moldofsky et al., 1986).

Extensive experimental data and clinical observations indicate that brain serotonin (5-hydroxytryptamine; 5 -HT) plays a pivotal role in the regulation of many physiological processes and complex behaviours (Jacobs \& Azmitia, 1992), including waking and sleep (Jouvet, 1999; Pace-Schott \& Hobson, 2002). Specifically, it has been proposed that 5-HT released during wakefulness promotes wakefulness per se, and triggers subsequent sleep via sleep-inducing factor(s) (Jouvet et al., 1983; Jouvet, 1999).

The IL-1 and serotonergic systems influence each other and exhibit a wide range of overlapping biological activities (Imeri \& De Simoni, 1999). IL-1 stimulates 5-HT release in the hypothalamus (Gemma et al., 1997) and other brain areas (Imeri \& De Simoni, 1999). An intact brain serotonergic system is necessary for the full manifestation of IL-1 effects on NREM sleep. Depletion of brain 5-HT (Imeri et al., 1997) or blockade of 5-HT2 receptors (Imeri et al., 1999) antagonizes part of IL-1-induced enhancement of NREM sleep. Collectively, these data suggest that IL-1 effects on NREM sleep are mediated, in part, by the serotonergic system (Imeri \& De Simoni, 1999).

As IL-1 microinjected into several brain regions (extending from the brain stem to the diencephalon) does not enhance NREM sleep (Walter et al., 1989), the site(s) in brain where IL-1 acts to enhance NREM sleep remain to be identified. Observations that IL-1 increases NREM sleep in part through the serotonergic system suggest a neurochemical 
substrate that might mediate IL-1 effects on NREM sleep. Because the dorsal raphe nucleus (DRN) is the origin of the major ascending serotonergic pathways to the forebrain (Jacobs \& Azmitia, 1992) and it contains IL-1 receptors (Cunningham \& De Souza, 1993; Schöbitz et al., 1994), the same observations also suggest that the DRN might represent one brain region that mediates IL-1 effects on NREM sleep.

The present study tested two distinct, yet related hypotheses. First, to test the hypothesis that the DRN represents one brain region where IL-1 acts to enhance NREM sleep, IL-1 $\beta$ was microinjected into the DRN of freely behaving rats and subsequent sleep-wake activity was quantified. Second, to test the hypothesis that the activity of DRN serotonergic neurons is modified by IL- $1 \beta$, intracellular recordings were obtained from physiologically and pharmacologically identified DRN serotonergic neurons using a guinea-pig brain stem slice preparation and changes induced by IL- $1 \beta$ in firing rate and membrane potential were determined.

\section{Materials and methods}

\section{Substances}

IL-1 $\beta$ (human recombinant IL-1 $\beta$ expressed in Escherichia coli) was purchased from R \& D System (Minneapolis, MN, USA). Lyophilized IL-1 $\beta$ was dissolved in pyrogen-free saline containing $0.1 \%$ bovine serum albumin, aliquoted, frozen and stored at $-80^{\circ} \mathrm{C}$ until used. Serotonin and noradrenaline (NA; Sigma, St Louis, MO, USA) used in the in vitro experiments were dissolved just prior to use in artificial cerebrospinal fluid (ACSF) of the following composition (mM): $\mathrm{NaCl}$ 120, $\mathrm{KCl} 2.5, \mathrm{KH}_{2} \mathrm{PO}_{4} 1.25, \mathrm{NaH}_{2} \mathrm{PO}_{4} 1.25, \mathrm{NaHCO}_{3} 22, \mathrm{MgSO}_{4} 2$, $\mathrm{CaCl}_{2}$ 2, glucose 10 (final $\mathrm{pH}$ 7.35) and applied via bath perfusion.

\section{In vivo experiments}

\section{Animals}

Male Sprague-Dawley rats (225-275 g at the time of surgery, Charles River, Calco CO, Italy) were anaesthetized (pentobarbital sodium $40 \mathrm{mg} / \mathrm{kg}+$ chloral hydrate $180 \mathrm{mg} / \mathrm{kg}$, intraperitoneally), positioned in a stereotaxic apparatus and surgically prepared for chronic polygraphic recordings. Stainless steel screws served as electroencephalographic (EEG) and ground electrodes after placement over frontal, parietal and occipital cortices. Teflon-coated silver wires were inserted in the neck muscles to record electromyographic activity. A calibrated $30-\mathrm{k} \Omega$ thermistor (Omega Engineering, Stamford, CT, USA) was implanted between the dura mater and the skull over the parietal cortex to monitor cortical brain temperature $\left(T_{\text {cort }}\right)$. A stainless steel guide cannula (length, $1.5 \mathrm{~cm}$; outer diameter, $0.5 \mathrm{~mm}$ ) was stereotaxically placed $3 \mathrm{~mm}$ above the DRN. In order to avoid damage to the midline sinus or to the Sylvius aqueduct, cannulae were implanted at a $30^{\circ}$ angle to the sagittal plane. The following stereotaxic coordinates (adapted from Paxinos \& Watson, 1986) were used: anterioposterior, $+0.7 \mathrm{~mm}$ from interaural line; lateral, $3.3 \mathrm{~mm}$; dorsoventral, $3.6 \mathrm{~mm}$ below the dura mater (tooth bar, $-3.3 \mathrm{~mm}$ ). Insulated leads were routed from the screws, the electromyographic electrodes, and the thermistor to a Teflon pedestal (Plastics One Inc., Roanoke, VA, USA) that was cemented in place with dental acrylic (Isocryl; Lang Dental Supply, Wheeling, IL, USA). The incision was treated topically with polysporin (polymixin B sulphate - bacitracin zinc) and the animals were placed under heat lamps and monitored until recovery from anaesthesia. On the third postsurgical day, the rats were connected to the recording apparatus (see later) via a flexible tether (connected to the Teflon pedestal) that allowed relatively unrestricted movement within the cage. For the next 5 days the animals were allowed to adapt to the experimental procedures before the experiments began. Rats were always housed individually in environmentally controlled chambers, maintained at $22 \pm 1{ }^{\circ} \mathrm{C}$ with a $12: 12 \mathrm{~h}$ light-dark cycle. Food and water were available ad libitum. Rats were fed a standard rat maintenance diet (Mucedola SRL, Settimo Milanese MI, Italy). All procedures involving animals and their care were conducted in conformity with institutional guidelines that are in compliance with European Union (EEC Council Directive 86/609, OJ L 358,1; 12 December 1987) and Italian (D.L.n.116, G.U. suppl. 40, 18 February 1992) laws and policies, as well as with the United States Department of Agriculture Animal Welfare Act and the United States Public Health Service Policy on Humane Care and Use of Laboratory Animals.

\section{Apparatus and recording}

Signals from the EEG and electromyographic electrodes as well as from the thermistor were fed into a Grass (Quincy, MA, USA) polygraph in the adjacent room. The EEG was amplified (factor of 3000 ) and analog bandpass filtered between 0.1 and $40 \mathrm{~Hz}$ (frequency response, $\pm 3 \mathrm{~dB}$; filter frequency roll off, $12 \mathrm{~dB}$ /octave). These conditioned signals were digitized with 12-bit precision at a sampling rate of $128 \mathrm{~Hz}$ (AT-MIO-64F5; National Instruments, Austin, TX, USA). The digitized EEG waveform, the $T_{\text {cort }}$ samples, and integrated values for EMG activity were stored as binary computer files until subsequent analyses. Post-acquisition determination of vigilance state was done by visual scoring of 12-s epochs using custom-written software. The animal's behaviour was classified as wakefulness, NREM or REM sleep. EEG power density values were obtained for each artefact-free $12-\mathrm{s}$ scoring epoch for the frequency range of $0.5-20 \mathrm{~Hz}$. Values in the $0.5-4.0 \mathrm{~Hz}$ (delta) frequency range were collapsed and integrated for 12 -s epochs, and used as measures of slow wave activity (SWA). These values for SWA were then matched to corresponding 12-s epochs that had already been scored for behavioural state to obtain SWA during NREM sleep.

\section{Experimental protocol}

Each animal was injected with both vehicle (pyrogen-free saline containing $0.1 \%$ bovine serum albumin) and at least one dose of IL- $1 \beta$, so each rat served as its own control. No animal received more than three microinjections, one vehicle and two IL-1 $\beta$. Animals also were studied in two further conditions: after simple handling for the time required by the microinjection procedure and after sham injection, during which an injection needle was inserted, but no microinjection made. Experiments were scheduled randomly with an interval of at least 3 days between microinjections. IL-1 $\beta$ and vehicle were administered $15 \mathrm{~min}$ prior to dark onset in a constant volume of $100 \mathrm{~nL}$, using a stainless steel needle (length, $1.8 \mathrm{~cm}$; outer diameter, $0.3 \mathrm{~mm}$ ), connected via polyethylene tubing to a Hamilton microsyringe and inserted through the guide cannula. The needle extended $3 \mathrm{~mm}$ past the tip of the guide cannula, reaching the DRN. Microinjections were performed over a 1min period. After the microinjection the needle was left in place for $3 \mathrm{~min}$. The highest IL- $1 \beta$ dose microinjected $(0.5 \mathrm{ng}, 29 \mathrm{fmol})$ corresponds to one-fifth of the lowest IL-1 dose that effectively enhances NREM sleep when administered intracerebroventricularly into rats (Opp et al., 1991; Lancel et al., 1996; Imeri et al., 1997). IL-1 $\beta$ and vehicle were dissolved, aliquoted and delivered using sterile procedures. Polygraphic recordings began immediately after the microinjections and continued for $12 \mathrm{~h}$.

At the end of the experiments an overdose of chloral hydrate was administered and dye was microinjected $(100 \mathrm{~nL})$ into the microinjection site; the brains were then removed and fixed. The position of the dye spot was determined from $40-\mu$ m-thick, frozen, neutralred-stained sections. In seven of 20 animals used in this study the histological examination of the site of injection revealed that the 

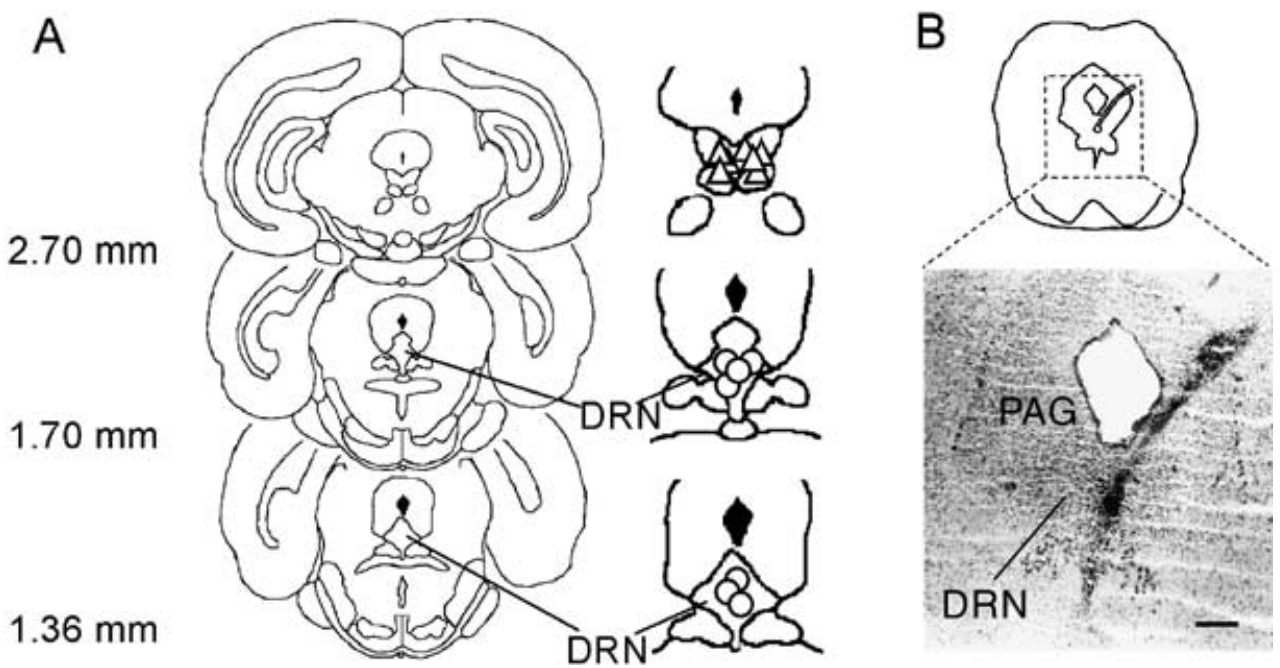

FIG. 1. (A) Schematic representation of location of microinjection sites described in this study. Coronal sections (left) and corresponding and enlarged details of the areas of interest (right) (from Paxinos \& Watson, 1986, with modifications). Distances (mm) are from the interaural line. Microinjection sites within the dorsal raphe nucleus (DRN) $(n=7)$ are represented by open circles. Microinjection sites outside and rostral to the DRN $(n=7)$, lying in the region of the oculomotor nucleus, are represented by open triangles. For the sake of clarity of the illustration, injection sites outside the DRN between coronal planes at $1.7 \mathrm{~mm}$ and $1.36 \mathrm{~mm}$ from the interaural line $(n=6)$ are not represented. (B) Microphotograph and schematic camera lucida drawing of a histological section showing track and site of microinjection into the DRN. Section shown corresponds approximately to the section at $1.7 \mathrm{~mm}$ from the interaural line shown in A. PAG, periaqueductal grey matter. Scale bar $=500 \mu \mathrm{m}$

injecting needle was in the DRN (Fig. 1A and B). In the remaining 13 animals the injection sites were located outside the DRN (Fig. 1A).

\section{Statistical analysis}

One-way analysis of variance (ANOVA) was used to determine if the experimental variables measured in this study were significantly different between the three control conditions tested (vehicle microinjection vs. needle insertion vs. handling). Dependent variables were: (i) amount of time spent in the different phases of the sleep-wake cycle, (ii) EEG SWA during NREM sleep, (iii) sleep architecture parameters and (iv) $T_{\text {cort }}$ values. 'Manipulation' was the main (fixed) effect. An $\alpha$ level of $P<0.05$ was taken to indicate a statistically significant difference between conditions.

One-way ANOVA was also used to determine if values obtained after administration of IL-1 deviated statistically from values obtained after vehicle microinjection. Experimental variables (see above) were the dependent variables and 'manipulation' (vehicle vs. IL-1 doses) the main (fixed) effect. On the basis of visual inspection of the results, statistical analyses were conducted across 2-h time blocks. An $\alpha$ level of $P<0.05$ was used to indicate a statistically significant difference between vehicle and IL-1. If ANOVA indicated statistically significant drug main effect, post hoc multiple comparisons were made using Fisher's least significant difference.

\section{In vitro experiments}

\section{Preparation of brain stem slices}

Guinea-pig brain slices were chosen for this study because they have been extensively used in the electrophysiological investigation of neurons involved in the regulation of sleep-wake activity and thermoregulatory mechanisms (see, for instance, Ono et al., 1987; Shibata \& Blatteis, 1991; Xin \& Blatteis, 1992; Bal \& McCormick, 1993; Leonard \& Llinas, 1994; Alonso et al., 1996; Khateb et al., 1998). Guinea-Pigs (Hartley strain, 150-175 g at time of experiment; Charles River, Italy) were anaesthetized with ether and decapitated. The brain then was removed rapidly and placed in ice-cold $\left(4{ }^{\circ} \mathrm{C}\right) \mathrm{ACSF}$, continuously bubbled with an $\mathrm{O}_{2}-\mathrm{CO}_{2}$ mixture $(95: 5 \%)$. Coronal sections ( $400 \mu \mathrm{m}$ thick) were then cut with a Vibratome ${ }^{\mathrm{B}}$ from a block of tissue containing the DRN in ice-cold carbogenated ACSF. Two slices were taken from each animal for subsequent in vitro recording. The slices were then incubated at room temperature in carbogenated ACSF and were left to recover for at least $1 \mathrm{~h}$. Then a single slice was transferred to a submersion-type slice recording chamber, through which carbogenated ACSF prewarmed to $34{ }^{\circ} \mathrm{C}$ was continuously superfused at a rate of $2.5 \mathrm{~mL} / \mathrm{min}$.

The DRN was located in the midline of the slice, between the medial longitudinal fasciculi extending dorsally towards the aqueduct. Only sections containing the midline decussating fibres of the superior cerebellar peduncle were selected for use. Intracellular recordings were made throughout the midline and paramidline DRN.

\section{Recording methods and electrophysiological characterization of serotonergic neurons}

Neurons were impaled with glass microelectrodes pulled from $1.5-\mathrm{mm}$ filament-containing tubing filled with $2 \mathrm{M}$ potassium-acetate (impedance, $60-80 \mathrm{M} \Omega$ ). Conventional intracellular recordings were made from DRN neurons using the bridge balance mode on an Axoclamp 2B amplifier. The bridge was frequently checked to ensure that it was balanced throughout experiments. Serotonergic DRN neurons were identified by their distinctive discharge and membrane properties (see in vitro results). Only spontaneously active neurons (about $80 \%$ of the impaled neurons) were included in the study. Neurons that did not display electrophysiological properties of serotonergic neurons $(<10 \%)$ were discarded and not further analysed. Because most of the serotonergic DRN neurons display a steady discharge, without sustained pauses or bursts in firing, their mean membrane potential was defined as the membrane potential value measured in the middle of each interspike interval. All neurons that met the electrophysiological criteria described above were further characterized pharmacologically (see in vitro results).

\section{In vitro drug application}

Test substances, dissolved in warmed carbogenated ACSF just prior to use and applied via bath perfusion, as described above, arrived in the bath 2 min after application. Serotonin and NA were applied for $1 \mathrm{~min}$. 
IL-1 was applied for $2 \mathrm{~min}$. The dose of IL-1 $\beta$ ( $25 \mathrm{ng} / \mathrm{mL} ; 1.5 \mathrm{nM})$ was chosen on the basis of previous in vitro electrophysiological studies (Miller et al., 1991; Shibata \& Blatteis, 1991; Pringle et al., 1996; D'Arcangelo et al., 1997). The effects of the different drugs were evaluated during intracellular recordings by comparing the mean neuronal discharge frequency and the membrane potential before any treatment (baseline record) and $3 \mathrm{~min}$ after their addition to the superfusing ACSF. All data are from neurons that showed recovery upon washout of applied substances.

\section{Data acquisition and analysis}

Signals were conditioned through an Axoclamp 2B amplifier (Axon, Foster City, CA, USA), followed online on a paper chart recorder, and continuously acquired onto a VHS tape recorder by means of an Instrutech VR 100B analog-digital converter (Instrutech Corp., Great Neck, NY, USA). The off-line analysis of data was performed with a Macintosh computer equipped with a direct memory access board (Instrutech ITC 16, Instrutech Corp.) and Axograph 4.6 software (Axon). One-way analysis of variance and Student's $t$-test, when appropriate, were used to determine if the electrophysiological variables investigated differed significantly between the three conditions tested (i.e. before, during and following substance application). Statistical differences were considered significant at $P<0.05$.

\section{Results}

\section{In vivo results}

\section{$I L-1 \beta$ enhanced NREM sleep when microinjected into the DRN}

NREM sleep was significantly increased for $2 \mathrm{~h}$ after microinjection of $0.5 \mathrm{ng}$ IL- $1 \beta$ into the DRN $(n=7)$ from $33.5 \pm 3.7 \%$ of recording time (after vehicle) to $42.9 \pm 3.0 \%(P<0.05$; Fig. 2, Table 1$)$. This increase
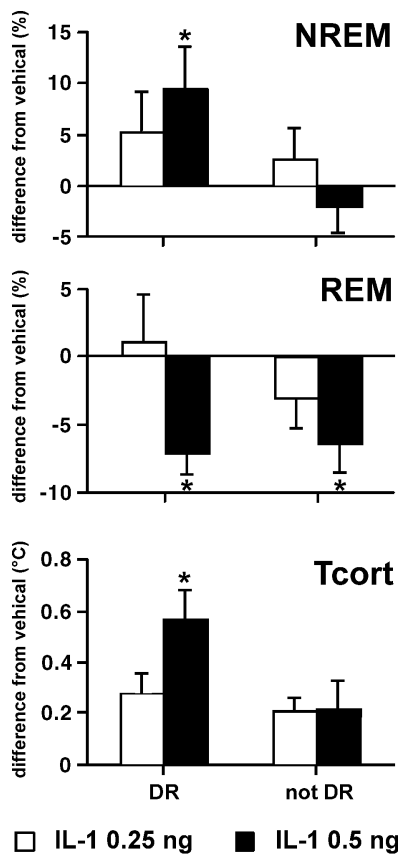

FIG. 2. Interleukin-1 (IL-1) microinjected into the dorsal raphe nucleus (DRN) increased non-rapid eye movements (NREM) sleep. Changes induced in NREM, rapid eye movements (REM) sleep, and brain cortical temperature ( $\left.T_{\text {cort }}\right)$ by IL-1 microinjection into the DRN and outside this area (not DRN) during the first $2 \mathrm{~h}$ post-injection. REM sleep was inhibited when IL-1 was microinjected both into and outside the DRN. Values are means $\pm \mathrm{SEM}$ and are expressed as differences from vehicle. ${ }^{*} P<0.05$ vs. vehicle. in the amount of NREM sleep was due to a significant increase in the number of NREM sleep bouts, from $17.1 \pm 1.8$ to $29.9 \pm 3.8$ $(P<0.05)$. EEG SWA during NREM sleep was not modified at any time after microinjection of $0.5 \mathrm{ng}$ IL-1 $\beta$.

In the first $2 \mathrm{~h}$ post-injection, $0.5 \mathrm{ng}$ IL-1 $\beta$ induced a significant decrease in the amount of REM sleep from $9.9 \pm 1.5 \%$ of recording time to $2.9 \pm 1.2 \%(P<0.05$; Fig. 2 , Table 1$)$. Amount of REM sleep was also reduced $3-4 \mathrm{~h}$ post-injection, from $8.2 \pm 1.7 \%$ of recording time (control condition) to $1.0 \pm 0.6 \%$ (Table 1). Owing to these changes in the amount of both NREM and REM sleep, the amount of NREM sleep/total sleep per cent ratio significantly increased from $77.3 \pm 3.2$ to $93.4 \pm 2.5(P<0.01)$. In the first $2 \mathrm{~h}$ post-injection, $0.5 \mathrm{ng}$ IL-1 $\beta$ also induced a fragmentation of the sleep-wake cycle, with a statistically significant increase in the number of transitions (from one state to another) from $79.6 \pm 8.8$ to $139.1 \pm 15(P<0.01)$. Over the same time interval, $0.5 \mathrm{ng}$ IL- $1 \beta$ significantly increased $T_{\text {cort }}$ from $37.0 \pm 0.1{ }^{\circ} \mathrm{C}$ (control condition) to $37.6 \pm 0.1{ }^{\circ} \mathrm{C}$ (Fig. 2, Table 1). At 3-4h post-injections, $0.5 \mathrm{ng}$ IL- $1 \beta$ significantly increased $T_{\text {cort }}$ from $37.3 \pm 0.1{ }^{\circ} \mathrm{C}$ (control condition) to $37.9 \pm 0.1{ }^{\circ} \mathrm{C}$ (Table 2 ). At the lower dose tested in this study $(0.25 \mathrm{ng}) \mathrm{IL}-1 \beta$ did not significantly affect sleep-wake activity (Fig. 2, Table 1), EEG SWA during NREM sleep and $T_{\text {cort }}$ (Fig. 2, Table 1).

When microinjections missed the DRN (Fig. 1), IL-1 $\beta$ did not alter the amount of NREM sleep (Fig. 2, Table 1) or EEG SWA during NREM sleep irrespective of dose and time. However, $0.5 \mathrm{ng}$ IL-1 $\beta$ microinjected outside the DRN significantly reduced REM sleep 1-2 $\mathrm{h}$ post-injection (from $11.2 \pm 1.6 \%$ after vehicle to $5.6 \pm 1.5 \%$ of recording time, $P<0.05$; Fig. 2, Table 1 ) and $3-4 \mathrm{~h}$ post-injection (from $7.9 \pm 1.1$ to $3.7 \pm 1.2 \%, P<0.05$; Table 1 ). The reduction in amoutn of REM sleep was due to a significant decrease in mean duration of REM bouts (from $1.7 \pm 0.2 \mathrm{~min}$ to $1.0 \pm 0.4 \mathrm{~min} ; P<0.05$ ). $T_{\text {cort }}$ was not altered by IL-1 $\beta$ during any of the post-injection time blocks (Fig. 2, Table 1). The lower IL-1 $\beta$ dose tested did not induce any significant change in sleep-wake activity (Fig. 2, Table 1), EEG SWA during NREM sleep and $T_{\text {cort }}$ (Fig. 2, Table 1).

Sham injection or vehicle microinjection into and outside the DRN did not alter sleep-wake behaviour and $\mathrm{T}_{\text {cort }}$

Values for experimental variables did not differ between the three control conditions tested (see above, Materials and methods - Experimental protocol), irrespective of whether the microinjection sites were located inside or outside the DRN (Table 2). The amount of time the rats spent in different vigilance states is consistent with values previously reported during control conditions for Sprague-Dawley rats during the dark phase of the light-dark cycle (Opp, 1997).

In vitro results

Serotonergic neurons in the DRN were inhibited by 5-HT and excited by $N A$

Thirty-five spontaneously active neurons were electrophysiologically characterized as serotonergic on the basis of their distinctive discharge and membrane properties (Williams et al., 1988): slow and regular firing rate (range, 0.5-4 Hz; Fig. 3A), large after-hyperpolarization (9$20 \mathrm{mV}$; Fig. 3A and B), high input resistance (150-400 M $\Omega$ ), long spike duration (1.5-2.5 ms; Fig. 3B). Because serotonergic neurons have been shown to be inhibited by 5 -HT and stimulated by NA (Baraban et al., 1978; Vandermaelen \& Aghajanian, 1983; Yoshimura \& Higashi, 1985; Williams et al., 1988), electrophysiologically identified neurons were further characterized pharmacologically. Following 5-HT perfusion, 32 of the 35 neurons either ceased firing (Fig. 3C) or their firing rate was significantly reduced. This reduction in firing rates from $1.4 \pm 0.3 \mathrm{~Hz}$ before 5 - $\mathrm{HT}$ perfusion to $0.2 \pm 0.1 \mathrm{~Hz}$ during 
TABLE 1. Effects of interleukin-1 (IL-1 $\beta$ ) microinjection into and outside the dorsal raphe nucleus (DRN) on the percentage of recording time spent in vigilance states and on average brain cortical temperature $\left(T_{\text {cort }}\right)$

\begin{tabular}{|c|c|c|c|c|c|c|}
\hline & \multicolumn{3}{|c|}{ Microinjection into DRN } & \multicolumn{3}{|c|}{ Microinjection outside DRN } \\
\hline & NREM & REM & $T_{\text {cort }}$ & NREM & REM & $T_{\text {cort }}$ \\
\hline \multicolumn{7}{|l|}{ Hours 1-2 } \\
\hline Vehicle & $33.5 \pm 3.7$ & $9.9 \pm 1.5$ & $37.0 \pm 0.1$ & $33.2 \pm 2.3$ & $11.2 \pm 1.6$ & $37.1 \pm 0.1$ \\
\hline IL-1 $\beta 0.25 \mathrm{ng}$ & $36.3 \pm 3.1$ & $10.7 \pm 2.5$ & $37.4 \pm 0.1$ & $37.0 \pm 2.9$ & $9.7 \pm 1.6$ & $37.2 \pm 0.1$ \\
\hline IL-1 $\beta 0.5 \mathrm{ng}$ & $42.9 \pm 3.0^{*}$ & $2.9 \pm 1.2^{*}$ & $37.6 \pm 0.1^{*}$ & $30.7 \pm 2.2$ & $5.6 \pm 1.5^{*}$ & $37.3 \pm 0.1$ \\
\hline \multicolumn{7}{|l|}{ Hours 3-4 } \\
\hline Vehicle & $38.4 \pm 4.5$ & $8.2 \pm 1.7$ & $37.3 \pm 0.1$ & $37.1 \pm 3.3$ & $7.9 \pm 1.1$ & $37.5 \pm 0.1$ \\
\hline IL- $1 \beta \quad 0.25 \mathrm{ng}$ & $34.0 \pm 2.5$ & $2.6 \pm 1.2$ & $37.8 \pm 0.1$ & $40.6 \pm 3.2$ & $4.3 \pm 1.1$ & $37.6 \pm 0.1$ \\
\hline $\mathrm{IL}-1 \beta 0.5 \mathrm{ng}$ & $40.8 \pm 1.9$ & $1.0 \pm 0.6^{*}$ & $37.9 \pm 0.1^{*}$ & $40.4 \pm 3.1$ & $3.7 \pm 1.2^{*}$ & $37.7 \pm 0.1$ \\
\hline \multicolumn{7}{|l|}{ Hours 5-6 } \\
\hline Vehicle & $34.3 \pm 4.9$ & $4.5 \pm 1.3$ & $37.4 \pm 0.1$ & $40.4 \pm 2.8$ & $10.9 \pm 1.5$ & $37.4 \pm 0.1$ \\
\hline IL- $1 \beta \quad 0.25 \mathrm{ng}$ & $36.6 \pm 3.8$ & $6.2 \pm 1.6$ & $37.7 \pm 0.1$ & $38.1 \pm 3.5$ & $5.8 \pm 1.3$ & $37.6 \pm 0.1$ \\
\hline IL-1 $\beta 0.5 \mathrm{ng}$ & $34.7 \pm 4.0$ & $6.6 \pm 1.9$ & $37.6 \pm 0.1$ & $38.9 \pm 3.0$ & $7.5 \pm 1.2$ & $37.6 \pm 0.1$ \\
\hline \multicolumn{7}{|l|}{ Hours 7-8 } \\
\hline Vehicle & $31.8 \pm 5.6$ & $7.2 \pm 1.7$ & $37.3 \pm 0.1$ & $27.9 \pm 2.8$ & $6.4 \pm 1.2$ & $37.4 \pm 0.1$ \\
\hline IL-1及 $0.25 \mathrm{ng}$ & $24.6 \pm 4.1$ & $8.5 \pm 2.7$ & $37.4 \pm 0.1$ & $34.2 \pm 4.2$ & $6.4 \pm 1.6$ & $37.4 \pm 0.1$ \\
\hline IL-1 $\beta 0.5 \mathrm{ng}$ & $32.9 \pm 5.0$ & $10.6 \pm 2.4$ & $37.2 \pm 0.1$ & $30.1 \pm 3.4$ & $9.3 \pm 1.4$ & $37.3 \pm 0.1$ \\
\hline \multicolumn{7}{|l|}{ Hours 9-10 } \\
\hline Vehicle & $27.1 \pm 4.0$ & $3.3 \pm 0.8$ & $37.2 \pm 0.1$ & $17.5 \pm 2.2$ & $2.5 \pm 0.7$ & $37.3 \pm 0.1$ \\
\hline IL-1 $\beta \quad 0.25 \mathrm{ng}$ & $22.6 \pm 4.1$ & $3.8 \pm 1.4$ & $37.2 \pm 0.1$ & $33.5 \pm 3.8$ & $5.5 \pm 1.3$ & $37.1 \pm 0.1$ \\
\hline IL-1 $\beta 0.5 \mathrm{ng}$ & $28.8 \pm 5.2$ & $5.8 \pm 1.5$ & $37.0 \pm 0.1$ & $20.6 \pm 3.1$ & $4.5 \pm 1.0$ & $37.2 \pm 0.1$ \\
\hline \multicolumn{7}{|l|}{ Hours $11-12$} \\
\hline Vehicle & $25.5 \pm 5.4$ & $3.4 \pm 1.3$ & $37.1 \pm 0.1$ & $15.4 \pm 3.5$ & $2.2 \pm 0.8$ & $37.2 \pm 0.1$ \\
\hline IL- $1 \beta \quad 0.25 \mathrm{ng}$ & $17.8 \pm 4.1$ & $3.8 \pm 1.3$ & $37.1 \pm 0.1$ & $23.0 \pm 2.7$ & $2.3 \pm 0.7$ & $37.0 \pm 0.1$ \\
\hline IL-1 $\beta 0.5 \mathrm{ng}$ & $28.3 \pm 5.2$ & $7.8 \pm 1.7$ & $36.8 \pm 0.1$ & $21.4 \pm 4.3$ & $4.9 \pm 1.5$ & $37.1 \pm 0.1$ \\
\hline
\end{tabular}

Values are the mean \pm SEM percentage of recording time within consecutive 2-h time blocks after administration of vehicle or two different doses of IL-1. ${ }^{*} P<0.05$ vs. vehicle.

5-HT perfusion $(P<0.001)$ was associated with membrane hyperpolarizations ranging from -2 to $-14 \mathrm{mV}$, with a mean value of $-6.4 \pm 1 \mathrm{mV}$ (from $-54.2 \pm 1.9 \mathrm{mV}$ before 5-HT perfusion to $-60.6 \pm 2.3 \mathrm{mV}$ during 5 -HT perfusion, $P<0.001)$. These effects were fully reversible: within $5 \mathrm{~min}$ after cessation of tissue exposure to 5 - $\mathrm{HT}$, firing rate and membrane potential returned to $1.2 \pm 0.2 \mathrm{~Hz}$ and $54.9 \pm 2.1 \mathrm{mV}$, respectively. The three neurons that were not inhibited by 5 -HT were not further analysed.

In 13 neurons, following IL-1 $\beta$ perfusion and full wash-out, perfusion with NA $30 \mu \mathrm{M}$ increased the firing rate from a baseline value of $1.5 \pm 0.3 \mathrm{~Hz}$ to $3.6 \pm 0.5 \mathrm{~Hz}(P<0.001$; Fig. 3D). This effect was associated with a mean depolarization of $1.9 \pm 0.6 \mathrm{mV}$ (from a resting membrane potential value of $-54.9 \pm 2.1 \mathrm{mV}$ before NA perfusion to
$-53.0 \pm 2 \mathrm{mV}$ during NA perfusion; $P<0.05)$. NA effects were fully reversible. The electrophysiological and neuropharmacological criteria used for the identification of DRN serotonergic neurons, first developed in rats, proved to be valid and reliable when used in guineapigs, for in vivo and in vitro extra- and intracellular elctrophysiological recordings (Craven et al., 1994, 2001; Mundey et al., 1994; Conley et al., 2002).

\section{IL-1 $\beta$ inhibited serotonergic DRN neurons}

Twenty-six $(81 \%)$ of 32 presumed serotonergic DRN neurons were inhibited by bath application of IL-1 ( $25 \mathrm{ng} / \mathrm{mL}$, Fig. 4$)$. IL-1 $\beta$ perfusion induced in these 26 neurons a significant decrease in spontaneous firing rate, from $1.6 \pm 0.2 \mathrm{~Hz}$ in control conditions to $0.8 \pm 0.2 \mathrm{~Hz}$

TABLE 2. Effects of handling, sham injection and vehicle administration into and outside the dorsal raphe nucleus (DRN) on the percentage of recording time spent in vigilance states and on average brain cortical temperature $\left(T_{\text {cort }}\right)$

\begin{tabular}{|c|c|c|c|c|c|c|}
\hline & \multicolumn{3}{|c|}{ Microinjection into DRN } & \multicolumn{3}{|c|}{ Microinjection outside DRN } \\
\hline & NREM & REM & $T_{\text {cort }}$ & NREM & REM & $T_{\text {cort }}$ \\
\hline \multicolumn{7}{|l|}{ Hours 1-2 } \\
\hline Handling & $32.7 \pm 7.9$ & $12.2 \pm 3.3$ & $37.1 \pm 0.1$ & $31.3 \pm 3.6$ & $10.7 \pm 2.2$ & $36.8 \pm 0.1$ \\
\hline Sham injection & $32.3 \pm 4.7$ & $9.7 \pm 2.5$ & $36.9 \pm 0.1$ & $31.2 \pm 4.4$ & $10.5 \pm 1.6$ & $37.0 \pm 0.1$ \\
\hline Vehicle & $33.5 \pm 3.7$ & $9.9 \pm 1.5$ & $37.0 \pm 0.1$ & $33.2 \pm 2.3$ & $11.2 \pm 1.6$ & $37.1 \pm 0.1$ \\
\hline \multicolumn{7}{|l|}{ Hours 1-12 } \\
\hline Handling & $28.8 \pm 2.7$ & $8.5 \pm 1.1$ & $37.2 \pm 0.1$ & $28.7 \pm 2.4$ & $8.7 \pm 1.3$ & $37.1 \pm 0.1$ \\
\hline Sham injection & $32.1 \pm 2.2$ & $7.3 \pm 0.8$ & $37.1 \pm 0.1$ & $31.7 \pm 1.8$ & $7.4 \pm 0.7$ & $37.3 \pm 0.1$ \\
\hline Vehicle & $31.8 \pm 1.9$ & $6.1 \pm 0.6$ & $37.2 \pm 0.1$ & $28.6 \pm 1.4$ & $6.9 \pm 0.6$ & $37.3 \pm 0.1$ \\
\hline
\end{tabular}

Values are the mean \pm SEM percentage of recording time for the first $2 \mathrm{~h}$ post-injection and for the whole recording period for the condition indicated. 
A

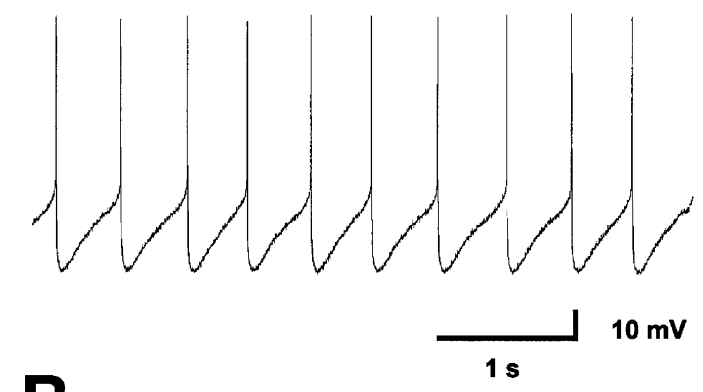

B

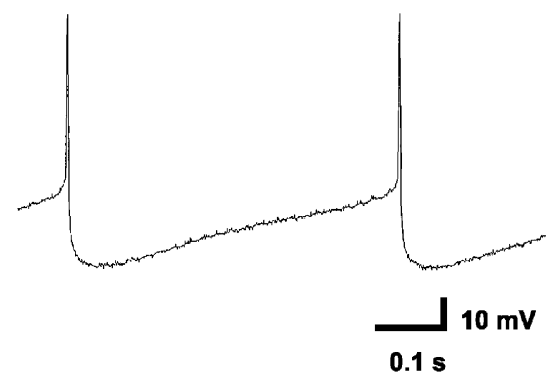

C

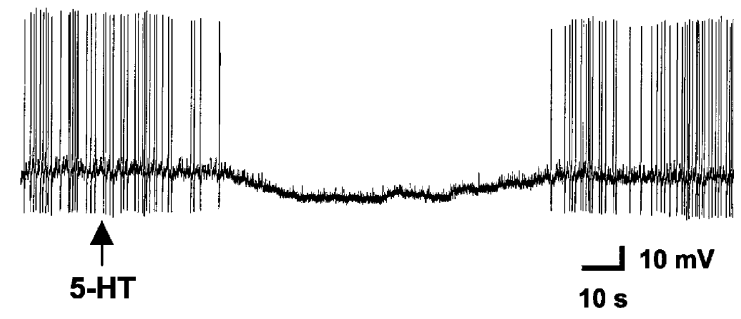

D

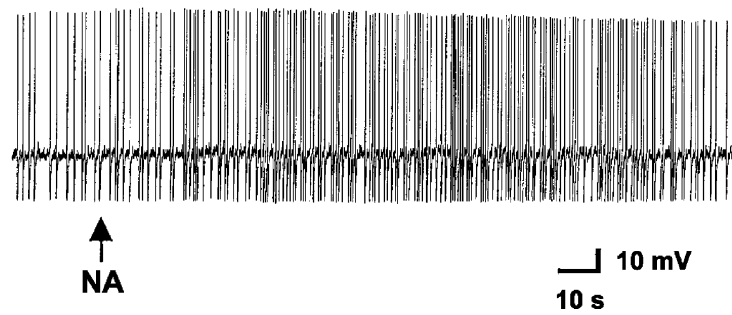

FIG. 3. Electrophysiological and pharmacological identification of serotonergic dorsal raphe nucleus (DRN) neurons. Representative voltage recordings from DRN serotonergic neurons obtained under current clamp in brain slice. No direct current current was injected. (A) Slow and regular firing rate of serotonergic DRN neurons in spontaneous conditions. (B) Detail of the recording in A, showing typical serotonergic action potentials, characterized by an initiating ramp of depolarization and by a large after-hyperpolarization. (C) Intracellular recording showing the effect of 1-min bath perfusion with 5HT $40 \mu \mathrm{M}$ (starting at arrow) on a serotonergic DRN neuron. In this case 5-HT induced a complete cessation of firing and a hyperpolarization of about $10 \mathrm{mV}$. (D) In the same neuron depicted in C, 1-min bath perfusion (starting at arrow) with NA $30 \mu \mathrm{M}$ induced a reversible increase in the firing rate. The effects in C and $\mathrm{D}$ were rapidly reverted after wash out.
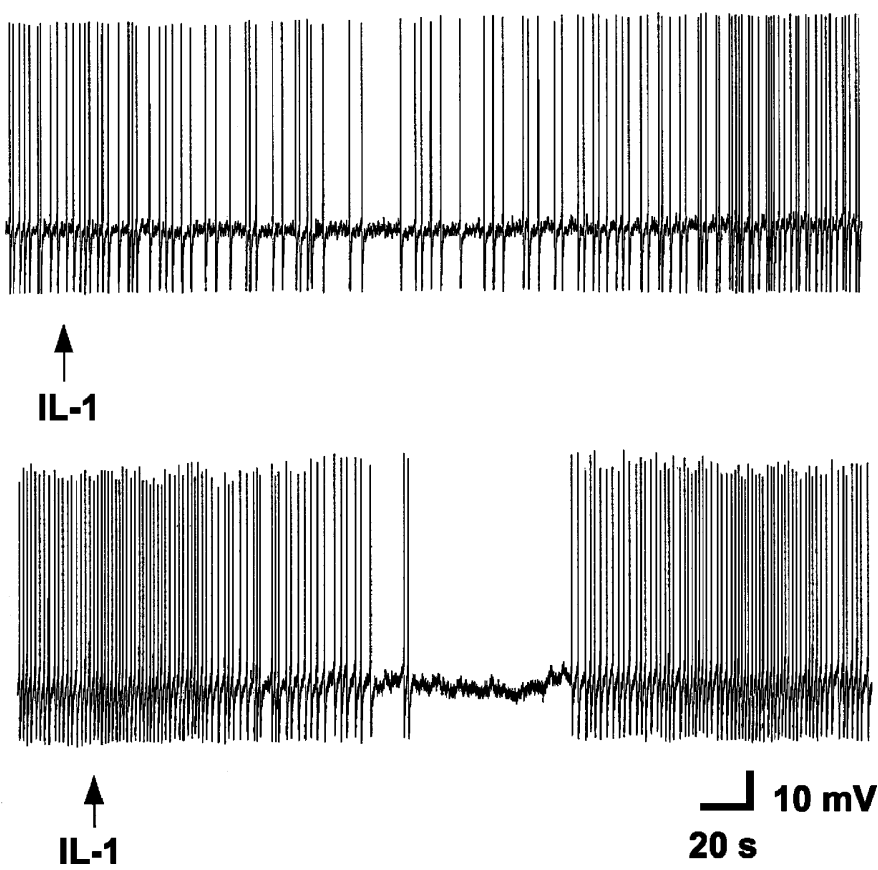

FIG. 4. Interleukin-1 (IL-1) inhibited serotonergic dorsal raphe nucleus (DRN) neurons intracellularly recorded in vitro. Intracellular recordings showing the effects of IL-1 $(25 \mathrm{ng} / \mathrm{mL})$ addition to bath perfusate for $2 \mathrm{~min}$ on two different representative serotonergic DRN neurons. Upper panel: IL-1 perfusion (starting at arrow) induced a decrease in spontaneous firing rate. Lower panel: in this neuron during perfusion with IL-1 the spontaneous activity first decreased and then ceased. In both neurons the effects were rapidly and completely reverted by washout.

during IL-1 $\beta$ perfusion. After wash-out, the firing rate returned to $1.6 \pm 0.3 \mathrm{~Hz}$. The IL-1 $\beta$-induced reduction in firing rate was associated with a non-significant membrane hyperpolarization. Three neurons were not responsive to IL- $1 \beta$. Three neurons were inhibited by IL-1 $\beta$, but data from these neurons were not analysed as the effect was not washable. None of the 32 neurons studied was depolarized or its spontaneous firing was increased by IL-1 $\beta$ perfusion.

\section{Discussion}

The results of the present study show that IL-1 $\beta$, when microinjected into the DRN (but not into adjacent brain stem areas) of freely behaving rats enhances NREM sleep. Furthermore, IL-1 $\beta$ inhibits the firing rates of physiologically and pharmacologically identified DRN serotonergic neurons in brain slice preparations. Collectively, these results suggest that IL- $1 \beta$ may increase NREM sleep by acting at the level of the DRN, perhaps due to the inhibition of DRN serotonergic neurons.

\section{IL-1 $\beta$ can enhance NREM sleep by acting at the level of the DRN}

Specific brain areas at which IL-1 can act to enhance NREM sleep remain to be fully identified, although there have been some studies to address this question. A purified IL-1 preparation obtained from stimulated human monocytes failed to enhance NREM sleep when microinjected into several areas of the rabbit brain, extending from the brain stem to the diencephalon and including areas in the rostral medulla, pons and midbrain, the hypothalamic preoptic area and basal forebrain, the posterior hypothalamus (Walter et al., 1989). Recent evidence suggests that IL-1 may alter NREM sleep by actions on the preoptic/anterior hypothalamic area; IL-1 increases firing rates of 
neurons active during NREM sleep and reduces firing rates of neurons active during waking (Alam et al., 2001). Consistent with these results are recent observations that IL-1 increases cytosolic $\mathrm{Ca}^{2+}$ in cultured hypothalamic neurons (De et al., 2002). IL-1, when microinjected into the rat locus coeruleus, potentiates EEG frequencies in the $3-9 \mathrm{~Hz}$ range and enhances sleep [as defined on the basis of visual inspection of the animal behaviour (De Sarro et al., 1997)]. By contrast, IL-1 induces wakefulness when microinjected into the rat hypothalamic paraventricular nucleus (Slisli \& de Beaurepaire, 1999). As IL-1 stimulates the release of corticotropin-releasing hormone (Barbanel et al., 1990), this latter effect is likely to be due to the increased levels of this peptide, which enhances wakefulness (Chang \& Opp, 2001).

The involvement of both IL-1 and 5-HT in sleep regulation, as well as growing evidence showing that IL-1-induced enhancement of NREM sleep is mediated, in part, by the serotonergic system, are rewieved in the Introduction. The DRN is the origin of the major ascending serotonergic pathways to the forebrain (Jacobs \& Azmitia, 1992) and it contains IL-1 receptors (Cunningham \& De Souza, 1993; Schöbitz et al., 1994). Therefore, the results of the present study, by demonstrating for the first time that IL- $1 \beta$ enhances polygraphically defined NREM sleep when microinjected into the DRN of conscious animals, indicate that the DRN might represent one brain region where IL-1 can affect the serotonergic system and, moreover, one brain region that mediates IL-1 effects on NREM sleep.

\section{IL-1 $\beta$ inhibits DRN serotonergic neurons}

Results in the present paper are the first to provide electrophysiological evidence that in brain slices IL- $1 \beta$ inhibits physiologically and pharmacologically identified DRN serotonergic neurons. As 5-HT is a wake-promoting agent (Jouvet, 1999; Pace-Schott \& Hobson, 2002), data in the present paper suggest that the increase in NREM sleep induced by IL- $1 \beta$ microinjection into the DRN can result, in part, from the inhibition of DRN serotonergic neurons.

Serotonin, which promotes wakefulness per se, also has been proposed to induce the synthesis and/or release of factor(s) that subsequently enhance sleep (Jouvet et al., 1983; Jouvet, 1999). Recent data directly support a dual role for 5-HT in sleep regulation. Increasing serotonergic activity by injecting rats with the 5-HT precursor 5hydroxytryptophan (5-HTP) first enhances wakefulness and later increases NREM sleep (Imeri et al., 2000).

The hypothalamic preoptic area and basal forebrain play a crucial role in the regulation of NREM sleep (reviewed in Jones, 2000; McGinty \& Szymusiak, 2000; Saper et al., 2001). IL-1 releases 5HT from axon terminals in the hypothalamus (Shintani et al., 1993), suggesting that IL-1 could promote NREM sleep not only by inhibiting wake-promoting DRN serotonergic neurons, but also by enhancing axonal 5-HT release in specific brain areas. The anterior hypothalamus is the only brain area where stimulation of serotonergic activity can restore physiological sleep in cats that have been made insomniac by brain 5-HT depletion (Denoyer et al., 1989). Serotonin hyperpolarizes basal forebrain cholinergic neurons responsible for cortical activation (Khateb et al., 1993). Furthermore, because 5-HT induces IL-1 both in vitro (Silverman et al., 1989) and in vivo (Gemma et al., 2003), it could amplify the effects of exogenously administered IL-1. These findings would explain previous results showing that 5-HT is necessary for the full manifestation of IL-1 effects on NREM sleep (reviewed in Imeri \& De Simoni, 1999). In summary, IL-1-induced NREM sleep enhancement could result from both the inhibition of the serotonergic cell bodies and the enhancement of 5-HT release from axon terminals in specific brain regions involved in NREM sleep generation. These effects may occur at different time points after IL-1 is administered or released in physiological or pathological conditions. They may also depend on sites in brain accessed by IL-1.

\section{IL-1 $\beta$-induced inhibition of REM sleep is not mediated by DRN serotonergic neurons}

The firing rate of DRN serotonergic neurons and 5-HT release from axon terminals are state-dependent: they are maximal during wakefulness, reduced during NREM sleep and suppressed (or minimal) during REM sleep (McGinty \& Harper, 1976; Trulson \& Jacobs, 1979; Cespuglio et al., 1981, 1990; Lydic et al., 1987; Wilkinson et al., 1991; Imeri et al., 1994; Portas \& McCarley, 1994). The observation that inhibition of the serotonergic system results in the enhancement of REM sleep (Adrien, 1995) suggests that suppressed serotonergic activity is permissive for REM sleep generation (Steriade \& McCarley, 1990; Pace-Schott \& Hobson, 2002). In vitro results of the present study indicate that IL-1 $\beta$ significantly reduces, but does not suppress, the firing rate of DRN neurons. In vivo results indicate that IL-1 $\beta$ microinjection into the DRN and adjacent brain stem areas does not increase, but rather inhibits, REM sleep. Taken together, these observations suggest that a reduced serotonergic activity is not sufficient to permit REM sleep, which could be enhanced only when serotonergic activity is abolished. Moreover, REM sleep is inhibited also by the noradrenergic neurons of the locus coeruleus (Pace-Schott \& Hobson, 2002), which were not targeted in this study.

Observations that blockade of 5-HT2 receptors (Imeri et al., 1999) does not modify IL-1-induced inhibition of REM sleep suggests that IL-1 inhibitory effects on REM sleep are not mediated by the serotonergic system (or at least not through this receptor subtype), but by other neurochemical systems. The possible spreading of IL-1 into adjacent cholinergic structures of the pontine tegmentum from microinjection sites within and outside the DRN cannot be ruled out. As the cholinergic system is involved in the generation of REM sleep (Steriade \& McCarley, 1990; Semba, 1999; Baghdoyan, 1997) and IL-1 inhibits ACh release in vivo in the hippocampus (Rada et al., 1991), as well as IL-1 synthesis in cultured pituitary cells (Carmeliet et al., 1989), IL-1 action on the cholinergic structures of the pontine tegmentum might account for the inhibition of REM sleep described in the present paper.

\section{IL-1 $\beta$-induced inhibition of DRN serotonergic neurons can increase brain cortical temperature}

IL-1 $\beta$ administration into the DRN nucleus induces a transient and moderate increase in $T_{\text {cort }}$. The typical response to IL-1 administration through several routes includes an increase in NREM sleep and a febrile response [reviewed in Terao et al., 1998; Opp \& Imeri, 1999; Krueger \& Fang, 2000). Although it is well established that, under certain circumstances, increases in body and brain temperature promote NREM sleep (reviewed in McGinty \& Szymusiak, 1990), an extensive literature shows that NREM sleep enhancement induced by IL-1 is a specific effect and it is not merely a byproduct of fever, because it occurs also when febrile response is blocked (Krueger et al., 1984; Opp et al., 1989).

Observations that IL- $1 \beta$ increases $T_{\text {cort }}$ when microinjected into the DRN, whereas no changes in $T_{\text {cort }}$ are observed when IL-1 is microinjected into brain stem areas surrounding the DRN, suggest that this IL-1 $\beta$ effect is due to specific actions on the DRN. Whereas the firing rate of serotonergic DRN neurons is not affected by the peripheral administration of synthetic muramyl dipeptide, an analogue of Grampositive bacterial cell wall component (Fornal et al., 1987), the present data show that DRN serotonergic neurons are inhibited by direct IL-1 $\beta$ administration.

Although the role of 5-HT in thermoregulation is complex, there is evidence that under certain conditions 5-HT may lower body/brain 
temperature, as 5-HT excites hypothalamic warm-sensitive neurons, inhibits cold-sensitive neurons and stimulates the release of proopiomelanocortin-derived peptides, including $\alpha$-melanocyte-stimulating hormone, whose hypothermic effect is well established (reviewed in Imeri et al., 2000). Observation that serotonergic activation induced by the administration of the 5-HT precursor 5-HTP decreases brain temperature (Imeri et al., 2000) supports such a role for 5-HT. The present results, showing that IL-1 inhibits DRN serotonergic neurons in brain slices and increases $T_{\text {cort }}$ when microinjected into the DRN of freely behaving animals, are in agreement with the hypothesis that 5HT lowers body/brain temperature and might explain the increase in $T_{\text {cort }}$ observed following IL-1 microinjection into the DRN.

In conclusion, the results presented here demonstrate for the first time that IL-1 $\beta$ enhances NREM sleep when microinjected into the DRN of conscious animals and inhibits the firing rates of DRN serotonergic neurons in a slice preparation. These data suggest that the DRN may be one specific brain region where IL- $1 \beta$ inhibits the wakepromoting serotonergic system, with subsequent enhancement of NREM sleep.

\section{Acknowledgements}

This work was supported, in part, by grants from the Ministero dell'Istruzione, dell'Università e della Ricerca Scientifica (Rome, Italy; L.I.), from the National Institute of Mental Health (Bethesda, MD, USA; MH 64843, M.R.O., L.I.) and from Sigma-Tau (Pomezia, Italy).

\section{Abbreviations}

5-HT, 5-hydroxytryptamine, serotonin; ACSF, artificial cerebrospinal fluid; DRN, dorsal raphe nucleus; EEG, elctroencephalogram/electroencephalographic; IL-1, interleukin-1; NA, noradrenaline; NREM, non-rapid eye movements; REM, rapid eye movements; SWA, slow wave activity; $T_{\text {cort }}$, cortical brain temperature.

\section{References}

Adrien, J. (1995) The serotoninergic system and sleep-wakefulness regulation. In Kales, A. (Ed.), The Pharmacology of Sleep. Springer-Verlag, Berlin, pp. 91-116.

Alam, M.N., McGinty, D., Imeri, L., Opp, M.R. \& Szymusiak, R. (2001) Effects of interleukin-1 beta on sleep- and wake-related preoptic/anterior hypothalamic neurons in unrestrained rats. Sleep, 24, A59.

Alonso, A., Khateb, A., Fort, P., Jones, B.E. \& Mühlethaler, M. (1996) Differential oscillatory properties of cholinergic and noncholinergic nucleus basalis neurons in guinea pig brain slice. Eur. J. Neurosci., 8, 169-182.

Baghdoyan, H.A. (1997) Cholinergic mechanisms regulating REM sleep. In Schwartz, W.J. (Ed.), Sleep Science: Integrating Basic Research and Clinical Practice. Karger, Basel, pp. 88-116.

Bal, T. \& McCormick, D.A. (1993) Mechanisms of oscillatory activity in guinea-pig nucleus reticularis thalami in vitro: a mammalian pacemaker. J. Physiol. (Lond.)., 468, 669-691.

Baraban, J.M., Wang, R.Y. \& Aghajanian, G.K. (1978) Reserpine suppression of dorsal raphe neuronal firing - mediation by adrenergic system. Eur. $J$. Pharmacol., 52, 27-36.

Barbanel, G., Ixart, G., Szafarczyk, A., Malaval, F. \& Assenmacher, I. (1990) Intrahypothalamic infusion of interleukin-1 beta increases the release of corticotropin-releasing hormone (CRH 41) and adrenocorticotropic hormone $(\mathrm{ACTH})$ in free-moving rats bearing a push-pull cannula in the median eminence. Brain Res., 516, 31-36.

Carmeliet, P., Van Damme, J. \& Denef, C. (1989) Interleukin-1 beta inhibits acetylcholine synthesis in the pituitary corticotropic cell line AtT20. Brain Res., 491, 199-203.

Cespuglio, R., Faradji, H., Gomez, M.E. \& Jouvet, M. (1981) Single unit recordings in the nuclei raphe dorsalis and magnus during the sleep-waking cycle of semi-chronic prepared cats. Neurosci. Lett., 24, 133-138.

Cespuglio, R., Sarda, N., Gharib, A., Chastrette, N., Houdouin, F., Rampin, C. \& Jouvet, M. (1990) Voltammetric detection of the release of 5-hydroxyindole compounds throughout the sleep-waking cycle of the rat. Exp. Brain Res., 80, 121-128.

Chang, F.C. \& Opp, M.R. (2001) Corticotropin-releasing hormone (CRH) as a regulator of waking. Neurosci. Biobehav. Rev., 25, 445-453.

Conley, R.K., Cumberbatch, M.J., Mason, G.S., Williamson, D.J., Harrison, T., Locker, K., Swain, C., Maubach, K., O’Donnell, R., Rigby, M., Hewson, L., Smith, D. \& Rupniak, N.M. (2002) Substance P (neurokinin 1) receptor antagonists enhance dorsal raphe neuronal activity. J. Neurosci., 22, 7730-7736.

Craven, R., Grahame-Smith, D. \& Newberry, N. (1994) WAY-100635 and GR127935: effects on 5-hydroxytryptamine-containing neurones. Eur. J. Pharmacol., 271, R1-R3.

Craven, R.M., Grahame-Smith, D.G. \& Newberry, N.R. (2001) 5-HT1A and 5HT2 receptors differentially regulate the excitability of 5-HT-containing neurones of the guinea pig dorsal raphe nucleus in vitro. Brain Res., 899 , $159-168$

Cunningham, E.T. Jr \& De Souza, E.B. (1993) Interleukin 1 receptors in the brain and endocrine tissues. Immunol. Today, 14, 171-176.

D'Arcangelo, G., Dodt, H.U. \& Zieglgansberger, W. (1997) Reduction of excitation by interleukin-1 beta in rat neocortical slices visualized using infrared-darkfield videomicroscopy. Neuroreport, 8, 2079-2083.

De, A., Churchill, L., Obal, F. Jr, Simasko, S.M. \& Krueger, J.M. (2002) GHRH and IL1beta increase cytoplasmic $\mathrm{Ca}(2+)$ levels in cultured hypothalamic GABAergic neurons. Brain Res., 949, 209-212.

De Sarro, G., Gareri, P., Sinopoli, V.A., David, E. \& Rotiroti, D. (1997) Comparative, behavioural and electrocortical effects of tumor necrosis factor-alpha and interleukin-1 microinjected into the locus coeruleus of rat. Life Sci., 60, 555-564.

Denoyer, M., Sallanon, M., Kitahama, K., Aubert, C. \& Jouvet, M. (1989) Reversibility of para-chlorophenylalanine-induced insomnia by intrahypothalamic microinjection of L-5-hydroxytryptophan. Neuroscience, 28, 83-94.

Fornal, C.A., Litto, W.J., Morilak, D.A. \& Jacobs, B.L. (1987) Single-unit responses of serotonergic dorsal raphe nucleus neurons to environmental heating and pyrogen administration in freely moving cats. Exp. Neurol., 98, 388-403.

Gemma, C., Imeri, L., De Simoni, M.G. \& Mancia, M. (1997) Interleukin-1 induces changes in sleep, brain temperature, and serotonergic metabolism. Am. J. Physiol., 272, R601-R606.

Gemma, C., Imeri, L. \& Opp, M.R. (2003) Serotonergic activation stimulates the pituitary-adrenal axis and alters interleukin-1 (IL-1) mRNA expression in rat brain. Psychoneuroendocrinology, 28, 875-884.

Gudewill, S., Pollmacher, T., Vedder, H., Schreiber, W., Fassbender, K. \& Holsboer, F. (1992) Nocturnal plasma levels of cytokines in healthy men. Eur. Arch. Psychiatry Clin. Neurosci., 242, 53-56.

Imeri, L., Bianchi, S. \& Mancia, M. (1997) Muramyl dipeptide and IL-1 effects on sleep and brain temperature after inhibition of serotonin synthesis. Am. J. Physiol., 273, R1663-R1668.

Imeri, L. \& De Simoni, M.G. (1999) Immune alterations in neurotransmission. In Lydic, R. \& Baghdoyan, H.A. (Eds), Handbook of Behavioral State Control: Cellular and Molecular Mechanisms. CRC Press, Boca Raton, FL, pp. 659-674.

Imeri, L., De Simoni, M.G., Giglio, R., Clavenna, A. \& Mancia, M. (1994) Changes in the serotonergic system during the sleep-wake cycle: simultaneous polygraphic and voltammetric recordings in hypothalamus using a telemetry system. Neuroscience, $\mathbf{5 8}, 353-358$.

Imeri, L., Mancia, M., Bianchi, S. \& Opp, M.R. (2000) 5-Hydroxytryptophan, but not L-tryptophan, alters sleep and brain temperature in rats. Neuroscience, 95, 445-452.

Imeri, L., Mancia, M. \& Opp, M.R. (1999) Blockade of 5-hydroxytryptamine (serotonin) -2 receptors alters interleukin-1-induced changes in rat sleep. Neuroscience, 92, 745-749.

Jacobs, B.L. \& Azmitia, E.C. (1992) Structure and function of the brain serotonin system. Physiol. Rev., 72, 165-229.

Jones, B.E. (2000) Basic mechanisms of sleep-wake states. In Kryger, M.H., Roth, T. \& Dement, W.C. (Eds), Principles and Practice of Sleep Medicine. W.B. Saunders, Philadelphia, pp. 134-154.

Jouvet, M. (1999) Sleep and serotonin: an unfinished story. Neuropsychopharmacology, 21, 24S-27S.

Jouvet, M., Sallanon, M., Petitjean, F. \& Bobillier, P. (1983) Serotonergic and non-serotonergic mechanisms in sleep. In: Gibson, C.J. \& Chase, M.H. (Eds), Sleep Disorders: Basic and Clinical Research. Spectrum, New York NY, pp. 557-571.

Khateb, A., Fort, P., Alonso, A., Jones, B.E. \& Mühlethaler, M. (1993) Pharmacological and immunohistochemical evidence for serotonergic modulation of cholinergic nucleus basalis neurons. Eur. J. Neurosci., 5, 541-547. 
Khateb, A., Fort, P., Williams, S., Serafin, M., Mühlethaler, M. \& Jones, B.E. (1998) GABAergic input to cholinergic nucleus basalis neurons. Neuroscience, 86, 937-947.

Krueger, J.M. \& Fang, J. (2000) Host defense. In Kryger, M.H., Roth, T. \& Dement, W.C. (Eds), Principles and Practice of Sleep Medicine. W.B. Saunders Co, Philadelphia, PA, pp. 255-265.

Krueger, J.M., Walter, J., Dinarello, C.A., Wolff, S.M. \& Chedid, L. (1984) Sleep-promoting effects of endogenous pyrogen (interleukin-1). Am. J. Physiol., 246, R994-R999.

Lancel, M., Mathias, S., Faulhaber, J. \& Schiffelholz, T. (1996) Effect of interleukin-1 beta on EEG power density during sleep depends on circadian phase. Am. J. Physiol., 270, R830-R837.

Leonard, C.S. \& Llinas, R. (1994) Serotonergic and cholinergic inhibition of mesopontine cholinergic neurons controlling REM sleep: an in vitro electrophysiological study. Neuroscience, 59, 309-330.

Lue, F.A., Bail, M., Jephthah-Ochola, J., Carayanniotis, K., Gorczynski, R. \& Moldofsky, H. (1988) Sleep and cerebrospinal fluid interleukin-1-like activity in the cat. Int. J. Neurosci., 42, 179-183.

Lydic, R., McCarley, R.W. \& Hobson, J.A. (1987) Serotonin neurons and sleep. I. Long term recordings of dorsal raphe discharge frequency and PGO waves. Arch. Ital. Biol., 125, 317-343.

Mackiewicz, M., Sollars, P.J., Ogilvie, M.D. \& Pack, A.I. (1996) Modulation of IL-1 beta gene expression in the rat CNS during sleep deprivation. Neuroreport, 7, 529-533.

McGinty, D.J. \& Harper, R.M. (1976) Dorsal raphe neurons: depression of firing during sleep in cats. Brain Res., 101, 569-575.

McGinty, D.J. \& Szymusiak, R.S. (1990) Keeping cool: a hypothesis about the mechanisms and functions of slow-wave sleep. Trends Neurosci., 13, $480-487$.

McGinty, D. \& Szymusiak, R. (2000) The sleep-wake switch: a neuronal alarm clock. Nature Med., 6, 510-511.

Miller, L.G., Galpern, W.R., Dunlap, K., Dinarello, C.A. \& Turner, T.J. (1991) Interleukin-1 augments gamma-aminobutyric acid A receptor function in brain. Mol. Pharmacol., 39, 105-108.

Moldofsky, H., Lue, F.A., Eisen, J., Keystone, E. \& Gorczynski, R. (1986) The relationship of Interleukin-1 and immune functions to sleep in humans. Psychosom. Med., 48, 309-318.

Mundey, M.K., Fletcher, A. \& Marsden, C.A. (1994) Effect of the putative 5-HT1A antagonists WAY100135 and SDZ. 216-525 on 5-HT neuronal firing in the guinea-pig dorsal raphe nucleus. Neuropharmacology, 33, 61-66.

Ono, T., Morimoto, A., Watanabe, T. \& Murakami, N. (1987) Effects of endogenous pyrogen and prostaglandin-E2 on hypothalamic neurons in guinea-pig brain-slices. J. Appl. Physiol., 63, 175-180.

Opp, M.R. (1997) Rat strain differences suggest a role for corticotropinreleasing hormone in modulating sleep. Physiol. Behav., 63, 67-74.

Opp, M.R. \& Imeri, L. (1999) Sleep as a behavioral model of neuro-immune interactions. Acta Neurobiol. Exp. (Warsz)., 59, 45-53.

Opp, M.R. \& Krueger, J.M. (1991) Inteleukin 1-receptor antagonist blocks interleukin 1-induced sleep and fever. Am. J. Physiol., 260, R453-R457.

Opp, M.R. \& Krueger, J.M. (1994a) Anti-interleukin-1 beta reduces sleep and sleep rebound after sleep deprivation in rats. Am. J. Physiol., 266, R688-R695.

Opp, M.R. \& Krueger, J.M. (1994b) Interleukin-1 is involved in responses to sleep deprivation in the rabbit. Brain Res., 639, 57-65.

Opp, M.R., Obál, F.J. \& Krueger, J.M. (1989) Corticotropin-releasing factor attenuates interleukin 1-induced sleep and fever in rabbit. Am. J. Physiol., 257, R528-R535.

Opp, M.R., Obál, F.J. \& Krueger, J.M. (1991) Interleukin 1 alters rat sleep: temporal and dose-related effects. Am. J. Physiol., 260, R52-R58.

Pace-Schott, E.F. \& Hobson, J.A. (2002) The neurobiology of sleep: genetics, cellular physiology and subcortical networks. Nature Rev. Neurosci., 3, $591-605$.
Paxinos, G. \& Watson, C. (1986) The Rat Brain in Stereotaxic Coordinates. Academic Press, San Diego, CA.

Portas, C.M. \& McCarley, R.W. (1994) Behavioral state-related changes of extracellular serotonin concentration in the dorsal raphe nucleus: a microdialysis study in the freely moving cat. Brain Res., 648, 306-312.

Pringle, A.K., Gardner, C.R. \& Walker, R.J. (1996) Reduction of cerebellar GABAA responses by interleukin-1 (IL-1) through an indomethacin insensitive mechanism. Neuropharmacology, 35, 147-152.

Rada, P., Mark, G.P., Vitek, M.P., Mangano, R.M., Blume, A.J., Beer, B. \& Hoebel, B.G. (1991) Interleukin-1 beta decreases acetylcholine measured by microdialysis in the hippocampus of freely moving rats. Brain Res., 550, 287-290.

Saper, C.B., Chou, T.C. \& Scammell, T.E. (2001) The sleep switch: hypothalamic control of sleep and wakefulness. Trends Neurosci., 24, 726-731.

Schöbitz, B., De Kloet, E.R. \& Holsboer, F. (1994) Gene expression and function of interleukin 1, interleukin 6 and tumor necrosis factor in the brain. Prog. Neurobiol., 44, 397-432.

Semba, K. (1999) The mesopontine cholinergic system: a dual role in REM sleep and wakefulness. In Lydic, R. \& Baghdoyan, H.A. (Eds), Handbook of Behavioral State Control. Cellular and Molecular Mechanisms. CRC Press, Boca Raton, FL, pp. 161-180.

Shibata, M. \& Blatteis, C.M. (1991) Differential effects of cytokines on thermosensitive neurons in guinea pig preoptic area slices. Am. J. Physiol., 261, R1096-R1103.

Shintani, F., Kanba, S., Nakaki, T., Nibuya, M., Kinoshita, N., Suzuki, E., Yagi, G., Kato, R. \& Asai, M. (1993) Interleukin-1 beta augments release of norepinephrine, dopamine, and serotonin in the rat anterior hypothalamus. J. Neurosci., 13, 3574-3581.

Silverman, D.H., Imam, K. \& Karnovsky, M.L. (1989) Muramyl peptide/ serotonin receptors in brain-derived preparations. Pept. Res., 2, 338-344.

Slisli, Y. \& de Beaurepaire, R. (1999) Interleukin-1beta and calcitonin, but not corticotropin-releasing factor, alter sleep cycles when injected into the rat hypothalamic lateral paraventricular area. Neurosci. Lett., 265, 29-32.

Steriade, M. \& McCarley, R.W. (1990) Brainstem Control of Wakefulness and Sleep. Plenum Press, New York.

Taishi, P., Bredow, S., Guha-Thakurta, N., Obál, F. Jr \& Krueger, J.M. (1997) Diurnal variations of interleukin-1 beta mRNA and beta-actin mRNA in rat brain. J. Neuroimmunol., 75, 69-74.

Terao, A., Matsumura, H. \& Saito, M. (1998) Interleukin-1 induces slow-wave sleep at the prostaglandin D2-sensitive sleep-promoting zone in the rat brain. J. Neurosci., 18, 6599-6607.

Trulson, M.E. \& Jacobs, B.L. (1979) Raphe unit activity in freely moving cats: correlation with level of behavioral arousal. Brain Res., 163, 135-150.

Vandermaelen, C.P. \& Aghajanian, G.K. (1983) Electrophysiological and pharmacological characterization of serotonergic dorsal raphe neurons recorded extracellularly and intracellularly in rat brain slices. Brain Res., 289, 109-119.

Vitkovic, L., Bockaert, J. \& Jacque, C. (2000) 'Inflammatory' cytokines: neuromodulators in normal brain? J. Neurochem., 74, 457-471.

Walter, J.S., Meyers, P. \& Krueger, J.M. (1989) Microinjection of interleukin-1 into brain: separation of sleep and fever responses. Physiol. Behav., 45, $169-176$.

Wilkinson, L.O., Auerbach, S.B. \& Jacobs, B.L. (1991) Extracellular serotonin levels change with behavioral state but not with pyrogen-induced hyperthermia. J. Neurosci., 11, 2732-2741.

Williams, J.T., Colmers, W.F. \& Pan, Z.Z. (1988) Voltage- and ligand-activated inwardly rectifying currents in dorsal raphe neurons in vitro. J. Neurosci., $\mathbf{8}$, 3499-3506.

Xin, L. \& Blatteis, C.M. (1992) Blockade by interleukin-1 receptor antagonist of IL-1-induced neuronal activity in guinea pig preoptic area slices. Brain Res., 569, 348-352.

Yoshimura, M. \& Higashi, H. (1985) 5-Hydroxytryptamine mediates inhibitory postsynaptic potentials in rat dorsal raphe neurons. Neurosci. Lett., 53, 69-74. 